\title{
Genetic analysis of the Fourier-transform infrared spectra of bovine milk with emphasis on individual wavelengths related to specific chemical bonds
}

\author{
G. Bittante and A. Cecchinato ${ }^{1}$ \\ Department of Agronomy, Food, Natural Resource, Animals and Environment (DAFNAE), University of Padova, Viale dell'Università 16, \\ 35020 Legnaro (PD), Italy
}

\begin{abstract}
Fourier-transform infrared (FTIR) spectra are used to predict the fat, protein, casein, and lactose contents of milk. These estimates are currently used to predict the individual estimated breeding values of animals. The objective of the present study was to estimate the genetic variation and heritabilities of the milk transmittance spectrum at each individual FTIR wave. Milk was sampled once per cow from a total of 1,064 Italian Brown Swiss cows from 30 herds, sired by 50 artificial insemination sires. The FTIR spectra of all samples were collected within $3 \mathrm{~h}$ of sampling from $25 \mathrm{~mL}$ of milk. The obtained spectral range comprised wavenumbers 5,000 to $930 \times \mathrm{cm}^{-1}$, corresponding to wavelengths 2.00 to $10.76 \mu \mathrm{m}$ and frequencies from 149.9 to $27.9 \mathrm{THz}$, for a total of 1,056 waves. These were acquired using a MilkoScan FT120 FTIR interferometer (Foss Electric A/S, Hillerød, Denmark). Each spectral data point was treated as a single trait and analyzed using an animal model REML method. The results indicated that the transmittance of the bovine milk FTIR spectrum was heritable for most individual waves in the wavenumber interval from 5,000 to $930 \times \mathrm{cm}^{-1}$. Moreover, the transmittance of contiguous FTIR waves was much more highly correlated in terms of the average value and phenotypic variation, compared with genetic variation. In the present study, we characterized 5 regions of the FTIR spectrum that were relevant to the analysis of milk; 2 regions, one in the transition area between the short-wavelength infrared (SWIR) and mid-wavelength infrared (MWIR) divisions of the electromagnetic spectrum (SWIR-MWIR region) and another very short region in the MWIR division (MWIR-2 region), were characterized by very high phenotypic variability in the transmittance of individual milk samples within each wave. This was caused by the absorption peaks of water, which can mask the effects of other important milk components. These regions also showed high ge-
\end{abstract}

Received January 16, 2013.

Accepted April 19, 2013.

${ }^{1}$ Corresponding author: alessio.cecchinato@unipd.it netic variability in transmittance, and the heritability estimates of individual waves were generally very low (with some exceptions). The 3 other identified regions contained many transmittance peaks that represented important chemical bonds; these showed much lower phenotypic and genetic variability in terms of individual waves, but relatively higher and less variable heritability estimates. Among them, the SWIR region (near-infrared) showed a peculiar cyclic pattern of the heritability coefficients of transmittance, the MWIR-1 region was particularly important for the estimation of fat, and the MWIR-LWIR region (also known also as the "fingerprint region") had 3 areas of relatively high heritability. In summary, we found that the transmittance data from the FTIR spectra of milk have genetic variability that may prove useful for the direct genetic improvement of dairy species, rather than only through indirect phenotypic predictions of individual milk quality and technological traits.

Key words: mid-infrared, spectroscopy, heritability, milk

\section{INTRODUCTION}

Near-infrared spectroscopy (NIRS) and mid-infrared spectroscopy (MIRS) have been widely used as secondary methodologies (requiring calibration based on primary wet analyses) for predicting the chemical and technological properties of different materials. The most-promising fields of application include uses in the agricultural products and food industries. For example, Karoui et al. (2010) reviewed the use of MIRS coupled with chemometrics for analyzing intact food systems and exploring the relationships between their molecular structures and quality. According to those authors, the main areas of research to date include quantitatively determining the main components of food and authenticating food products, particularly those produced using traditional technologies in limited production regions. Attempts have also been made to predict the technological and sensorial properties of food, as well as their areas of origin and typicality. However, much more research is warranted in these fields. 
The use of the NIRS and MIRS has spread largely because (1) they require little or no sample pretreatment; (2) they are nondestructive; (3) they do not require chemicals or other consumables; (4) the spectra are obtained very rapidly and often automatically; (5) the spectra can be retrieved using portable instruments at the farm, industry, retail, or domestic levels; (6) for some applications (and given specific probes), the spectra can be retrieved from the surface of intact unsampled materials; (7) customized, simplified instruments are available for continuous monitoring "at line" during the processing of food; (8) the data contained within the spectra are very complex and can reflect both physical states and molecular structures; (9) the spectral data are easily stored; (10) given the availability of proper calibrations, one spectrum can be simultaneously used for several chemical/physical predictions; (11) spectral information can provide a very complex description of samples (a "fingerprint") that can be useful in describing the quality and typicality of food; and (12) when a new calibration becomes available for a trait (whether old or new), the stored spectra of samples that are no longer physically available can be reevaluated using this calibration.

One of the most widespread uses of MIRS is to predict the chemical composition and technological properties of milk (Barbano and Lynch, 2006; Woodcock et al., 2008; Brandt et al., 2010). In the cheese-making industry, MIRS is widely used to monitor milk processing and cheese making (Laporte et al., 1998; O'Callaghan et al., 2002; Leitner et al., 2011), to evaluate specific chemical or technological aspects of the products (Payne et al., 1993; Fagan et al., 2007b; Koca et al., 2007; Martíndel-Campo et al., 2007), to predict the sensory traits of cheese (Fagan et al., 2007a; Subramanian et al., 2009), and to assess the individuality and origin of cheese (Pillonel et al., 2003; Karoui et al., 2005a,b).

Fourier-transform infrared (FTIR) spectrometry, which is a type of MIRS that allows users to rapidly scan a complete spectrum of electromagnetic waves (Karoui et al., 2010), is commonly used to analyze milk samples that are collected periodically according to the milk-recording schemes of different countries. The International Committee for Animal Recording (ICAR, 2012) has approved FTIR spectrometry as the standardized routine method for analyzing the fat, protein, and lactose contents of milk. Fourier-transform infrared spectrometry has also been proposed for the population-level analysis of other milk components, such as fatty acids (Rutten et al., 2009; De Marchi et al., 2011; Soyeurt et al., 2011), protein fractions (van der Ven et al., 2002; Bonfatti et al., 2011; Rutten et al., 2011), enzymes (Soyeurt et al., 2008b), and minerals (Wu et al., 2009; Soyeurt et al., 2009). Moreover, FTIR has been proposed for the prediction of milk coagulation properties and titratable acidity (Dal Zotto et al., 2008; De Marchi et al., 2009).

Fourier-transform infrared spectrometry-based predictions of milk fat and protein (casein) contents are currently used to estimate the breeding value of animals. However, researchers are also interested in predicting other milk-related selection objectives from the same spectral information, as in the genetic evaluation of FTIR spectrometry-predicted FA (Soyeurt et al., 2007b, 2008a; Rutten et al., 2010), protein fractions (Soyeurt et al., 2007a; Arnould et al., 2009), and coagulation properties (Cecchinato et al., 2009; Bittante et al., 2012). Notably, FTIR spectrometry-based predictions of milk FA are also currently being investigated as indirect measures of an animal's body energy status (McParland et al., 2011) and fertility (Bastin et al., 2012), and NIRS has been proposed as an indirect tool for selecting beef cattle for meat quality (Cecchinato et al., 2011a, 2012).

The measure of some physical property of a biological sample (for example, the absorbance or transmittance of milk at specific wavelengths) is determined by its chemical properties (the presence of specific chemical bonds and the structures of lactose, caseins, whey proteins, and fat, among others). This chemical composition is the result of a physiological process (milk synthesis in the mammary gland) that is subject to genetic control (the major genes and polygenic effects on milk yield). Each step of this process, starting from physical measures of milk and ending with the genetics of the cow, have been extensively studied. Moreover, the same spectral information can be used to predict multiple chemical or technological traits of the animal product, each of which is characterized by different physiological processes and genetic controls. The present study sought to directly link the genetics of a cow and the mid-infrared (MIR) transmittance of her milk, and to estimate the genetic variation and heritabilities of the transmittance of individual wavelengths in relation to the area of the spectrum and their phenotypic variability, with a special emphasis on the wavelength characteristics of specific chemical bonds and milk constituents.

\section{MATERIALS AND METHODS}

\section{Sample Collection and MIR Spectra Acquisition}

A total of 1,200 Brown Swiss cows reared in 30 herds, offspring of $50 \mathrm{AI}$ sires and located in northern Italy, were milk sampled once. After initial data screening and removal of records with incomplete information, 1,064 samples were available for the study. The aver- 
age number of DIM and milk yield for the selected cows were $201 \pm 121 \mathrm{~d}$ and $28 \pm 8 \mathrm{~kg} / \mathrm{d}$, respectively. After collection, milk samples (without any preservative) were stored in portable refrigerators $\left(4^{\circ} \mathrm{C}\right)$ and transferred to the milk quality laboratory of Veneto Agricoltura (Thiene, Italy).

Fourier-transform infrared spectra were collected within $3 \mathrm{~h}$ of sampling from $25-\mathrm{mL}$ samples over the spectral range of wavenumbers 5,000 to $930 \times \mathrm{cm}^{-1}$, which corresponded to wavelengths 2.00 to $10.76 \mu \mathrm{m}$ and frequencies from 149.9 to $27.9 \mathrm{THz}$, for a total of 1,056 waves. This analysis was performed using a MilkoScan FT120 FTIR interferometer (Foss Electric A/S, Hillerød, Denmark). As water represents the major constituent of milk, and the transmittance spectrum (transmittance is the radiation passing through the sample as percentage of the incident radiation) of milk is very similar to that of water (Kaylegian et al., 2009), water transmittance can mask the transmittance due to the other milk components. For this reason the transmittance spectrum of milk is "zeroed" for the spectrum of water expressing, for each wavelength considered, the transmittance of milk sample $\left(I_{\text {milk }}\right)$ as a ratio respect to the transmittance of the reference $\left(I_{\text {water }}\right)$ :

$$
T=\frac{I_{\text {milk }}}{I_{\text {water }}}
$$

Usually transmittance of milk is lower than that of water because of the presence of other components, and so the ratio $T$ is $<1$. But it can be also $>1$ for the wavelengths not much affected by other substances because the quantity of water in milk is less than in $100 \%$ water reference. As the concentration of a given substance in milk is proportional to the radiation absorbance $(A)$, this is calculated from zeroed transmittance:

$$
A=-\log _{10} T=\log _{10} T^{-1},
$$

when the transmittance of milk is equal to that of water, and so $T=1, A=0$; when $T<1, A$ is positive, and when $T>1, A$ is negative. The obtained absorbance spectra of milk samples corrected for water are automatically standardized by the instrument to correct for shifts in wavelength scale, in absorbance scale, or in both. Duplicate transmittance measurements for each wave were captured for each sample and averaged before data analysis. Further details regarding the animals and analyses can be found in De Marchi et al. (2009) and Cecchinato et al. (2009).

Pedigree information was supplied by the Italian Brown Swiss Cattle Breeders Association [Associazione Nazionale degli Allevatori di Razza Bruna (ANARB), Verona, Italy], and included cows with phenotypic re- cords for the investigated traits and all their known ancestors. Each animal with phenotypic records had at least 4 known ancestors included in the pedigree data.

\section{Statistical Analysis}

Variance components for each of the 1,056 spectral data points were estimated by a single-trait REML animal model using the VCE software (Groeneveld, 1996). For each of the 1,056 traits the following linear model was used:

$$
\mathrm{y}_{\mathrm{ijklm}}=\mu+\operatorname{Herd}_{\mathrm{i}}+\operatorname{Dim}_{\mathrm{j}}+\operatorname{Parity}_{\mathrm{k}}+\operatorname{anim}_{1}+\varepsilon_{\mathrm{ijklm}},
$$

where $\mathrm{y}_{\mathrm{ijklm}}$ was the transmittance at a wavelength, $\mu$ was the intercept of the model, $\operatorname{Herd}_{i}(i=1, \ldots, 30)$ was the fixed effect of the herd, $\operatorname{Dim}_{j}(j=1, \ldots, 10)$ was the fixed effect of the class of days in milk, Parity was the fixed effect of the class of parity $(\mathrm{k}=1, \ldots$, $3)$, anim $_{1}$ was the random additive genetic effect of the animal $(1=1, \ldots, 9,934)$, and $\varepsilon_{\mathrm{ijklm}}$ was a random residual. In matrix form the mixed linear model was

$$
\mathbf{y}=\mathbf{X} \boldsymbol{\beta}+\mathbf{Z u}+\mathbf{e},
$$

where $\mathbf{y}$ was a vector of measures of a single spectrum data point, $\boldsymbol{\beta}$ was a vector of nongenetic effects, $\mathbf{u}$ was a vector of additive polygenic effects of animals, and $\mathbf{e}$ was a vector of residual. The terms $\mathbf{X}$ and $\mathbf{Z}$ were known incidence matrices relating observations to $\boldsymbol{\beta}$ and $\mathbf{u}$, respectively. The distributional assumption about the random terms of the model was

$$
\left[\mathbf{u}^{\prime} \mathbf{e}^{\prime}\right]^{\prime} \sim N\left(\mathbf{0}^{*}, \Phi\right),
$$

where $0^{*}$ was a column vector with dimension equal to the total number of elements in $\mathbf{u}$ and $\mathbf{e}$, and the dispersion term was defined as

$$
\boldsymbol{\Phi}=\left[\begin{array}{cc}
\mathbf{A} \sigma_{a}^{2} & \mathbf{0} \\
\mathbf{0} & \mathbf{I} \sigma_{e}^{2}
\end{array}\right],
$$

where $\sigma_{a}^{2}$ was the additive genetic variance, $\sigma_{e}^{2}$ was the residual variance, $\mathbf{A}$ was the numerator relationship matrix (Wright, 1922), I was the identity matrix, and $\mathbf{0}$ was a null matrix of appropriate order. Effects included in $\boldsymbol{\beta}$ were the effects of the class of DIM, class of parity (first, second, and third or greater parity) and herd test day.

\section{RESULTS}

\section{Descriptive Statistics of Bovine Milk Spectra}

The 1,056 average transmittances obtained from 1,064 cows' milk samples, analyzed for each of the individual 

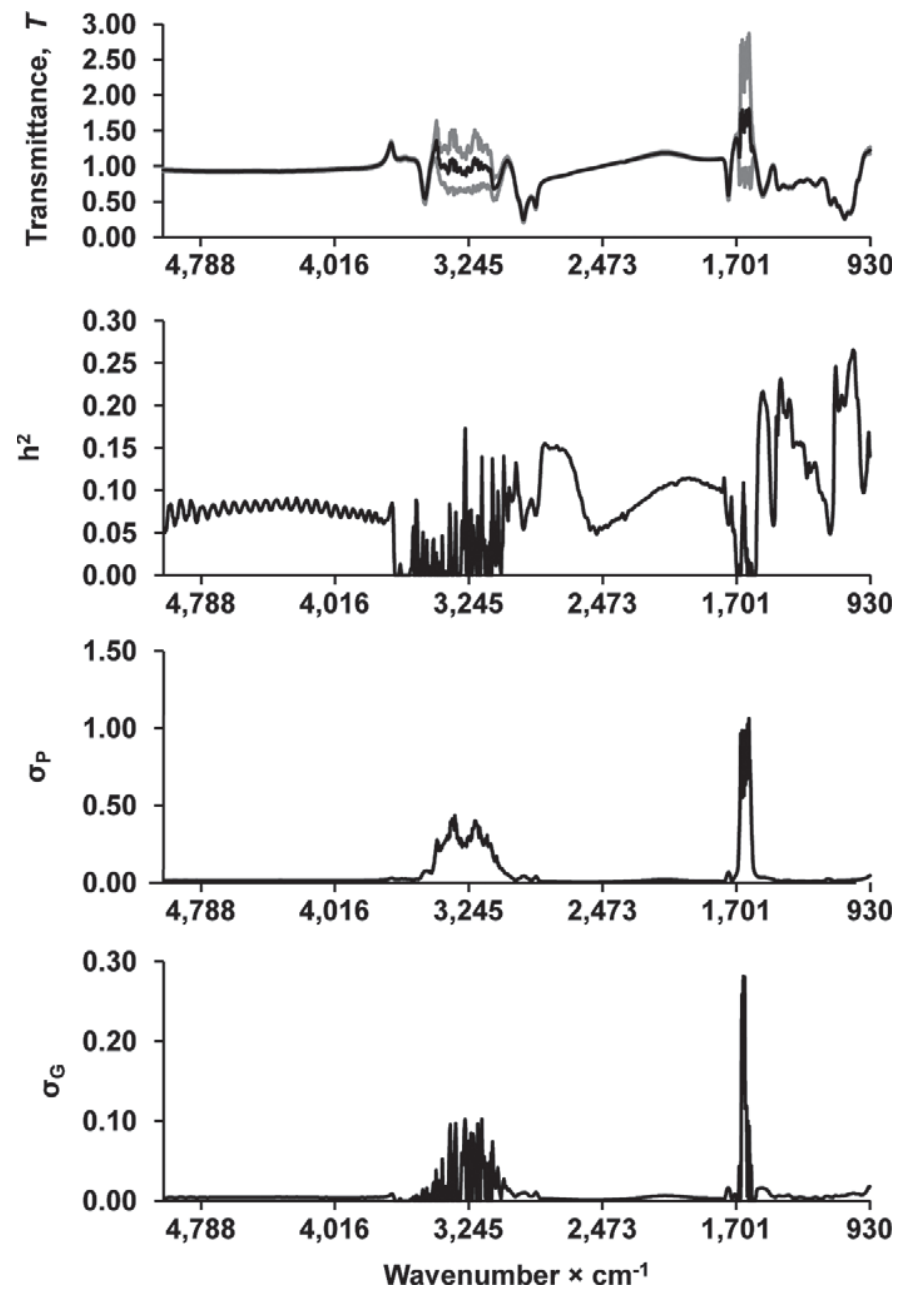

Figure 1. Plots showing the transmittance ( $T$; solid black line represents the average and the 2 gray lines represent the average \pm $\mathrm{SD})$, the heritability $\left(\mathrm{h}^{2}\right)$, the phenotypic standard deviation $\left(\sigma_{\mathrm{P}}\right)$, and the genetic standard deviation $\left(\sigma_{\mathrm{G}}\right)$ of 1,056 individual infrared wavelengths measured for 1,064 milk samples of individual cows according to their frequency (wavenumber $\times \mathrm{cm}^{-1}$ ).
FTIR waves tested, are shown in Figure 1 according to their wavenumbers. The infrared region considered spanned from wavelength $2.0 \mu \mathrm{m}$ (corresponding to a wavenumber of $5,000 \times \mathrm{cm}^{-1}$ and a frequency of 149.9 $\mathrm{THz}$ ) to wavelength $10.8 \mu \mathrm{m}$ (corresponding to a wavenumber of $930 \times \mathrm{cm}^{-1}$ and a frequency of $27.9 \mathrm{THz}$ ).

The transmittance values of many electromagnetic waves in the FTIR spectra of cow milk were found to be heritable, in that they were at least partly controlled by the additive effect of the cow's genes. The heritability estimates of the absorbance of milk for each FTIR wave considered are shown in Figure 1, together with their phenotypic and genetic standard deviations.

\section{The Genetic Components of the FTIR Spectra}

Of the 1,056 mixed animal models (one for each examined FTIR wave), about $16 \%$ yielded heritability estimates that were null or lower than $5 \%$, and were thus on the same order as the standard error of the estimates (Table 1). More than half (55\%) of the FTIR waves exhibited low heritability estimates for their transmittance (between 5 and 10\%). Slightly more than $18 \%$ had heritability estimates between 10 and $15 \%$, whereas about 6 and $4 \%$ had moderate heritabilities in the intervals of 15 to $20 \%$ and 20 to $25 \%$, respectively. Less than $1 \%$ of the FTIR waves had heritability coefficients greater than $25 \%$.

The FTIR waves that yielded null or very low heritabilities had an average transmittance that was highly variable but similar to the average figures for all the other waves; however, their phenotypic and residual standard deviations were, on average, 4.6 and 4.7 times greater than the corresponding average figures for all the other waves. Their genetic standard deviations were greater than the general value on average, but only by 1.6 times (Table 1); therefore, the low heritability for the transmittance of these waves was more frequently due to an increase in residual variance than a reduc-

Table 1. Estimates of phenotypic $\left(\sigma_{\mathrm{P}}\right)$, residual $\left(\sigma_{\mathrm{E}}\right)$, and genetic $\left(\sigma_{\mathrm{G}}\right) \mathrm{SD}$ and heritability $\left(\mathrm{h}^{2}\right)$ for 1,056 mid-infrared individual wavelength (WL) transmittance values measured from milk samples of 1,064 cows, according to the class of heritability

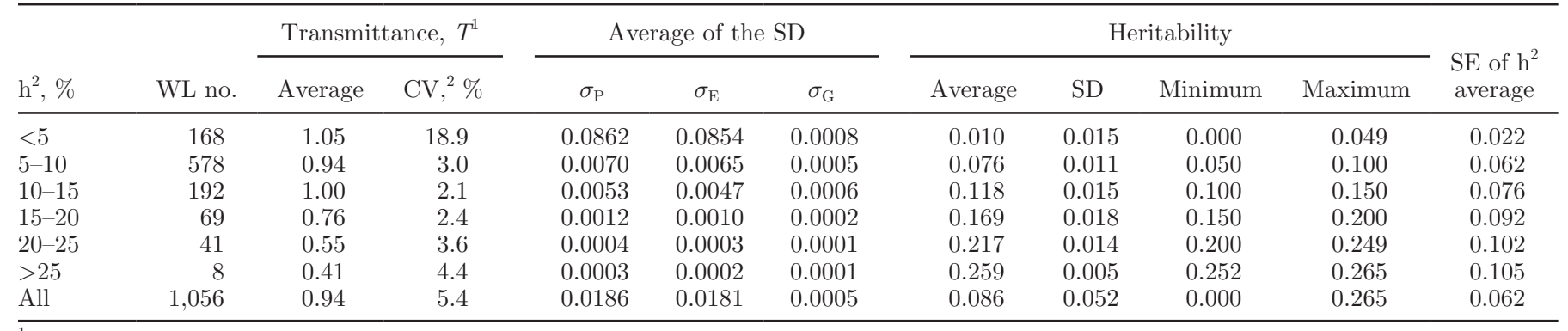

${ }^{1}$ Mean values of each WL of the class.

${ }^{2}$ Coefficient of variation of the mean values of each WL of the class. 
tion in genetic variance. Correspondingly, the FTIR waves whose transmittance showed relatively high heritability tended to have lower average transmittance values $(-61 \%)$, much lower genetic standard deviations $(-91 \%)$, and even lower phenotypic and residual standard deviations ( $-99.6 \%$ and $-99.7 \%$, respectively). From this, we clearly see that the transmittance of different FTIR waves is determined far more by the phenotypic variability among individual samples than by the average value.

For the 1,064 individual milk samples analyzed, the relationships between the phenotypic variability of the transmittance of each FTIR wave and the corresponding estimates of genetic parameters are reported in Table 2, where the data of the different FTIR waves are grouped in classes of increasing phenotypic standard deviation, according to a factor 10. An increase in the phenotypic variability of the FTIR waves was not accompanied by a parallel increase in their average transmittance (with the partial exception of the last class), but it was accompanied by a large increase in the variability of the average transmittance (from 0.7 to $40.9 \%$ ). Thus, the FTIR waves that were characterized by very large variability of transmittance among individual samples could be grouped based on high, medium, or low average transmittance (Table 2). The very large increase in the phenotypic standard deviation of transmittance (on average, the 40 FTIR waves of the last class were 7,130 times more variable than the 190 waves of the first class) was paralleled by a corresponding increase in residual variability $(+8,655$ times) and a moderate increase in genetic variability $(+1,027$ times). This explains why, on average, the heritability decreased from $10.2 \%$ in the first class of waves to $2.7 \%$ in the last 2 classes (Table 2). The percentage of FTIR waves characterized by little or no heritability (lower than $5 \%$ ) increased from $1 \%$ of the first class to 79 and $75 \%$ of the last 2 classes, respectively (Table 2).

The relationships between the heritability of an individual FTIR wave and its average transmittance, phenotypic standard deviation, and coefficient of variability are illustrated in Figure 2. Clearly, the distribution of individual FTIR waves is far from the expected for normally distributed traits. Moreover, although the waves with higher average transmittance or phenotypic variability all have low heritability coefficients, the heritability of individual waves is not strongly related to their average transmittance values $\left(\mathrm{R}^{2}=20 \%\right)$, phenotypic standard deviations $\left(\mathrm{R}^{2}=14 \%\right)$, or coefficients of variability $\left(\mathrm{R}^{2}=15 \%\right)$.

We tested 1,056 individual FTIR waves at wavenumber intervals of 3.85 (from 5,000 to $930 \times \mathrm{cm}^{-1}$ ), corresponding to an average wavelength increase of 8.3 $\mathrm{nm}$ (from 2.00 to $10.76 \mu \mathrm{m}$ ). To study the relative in-

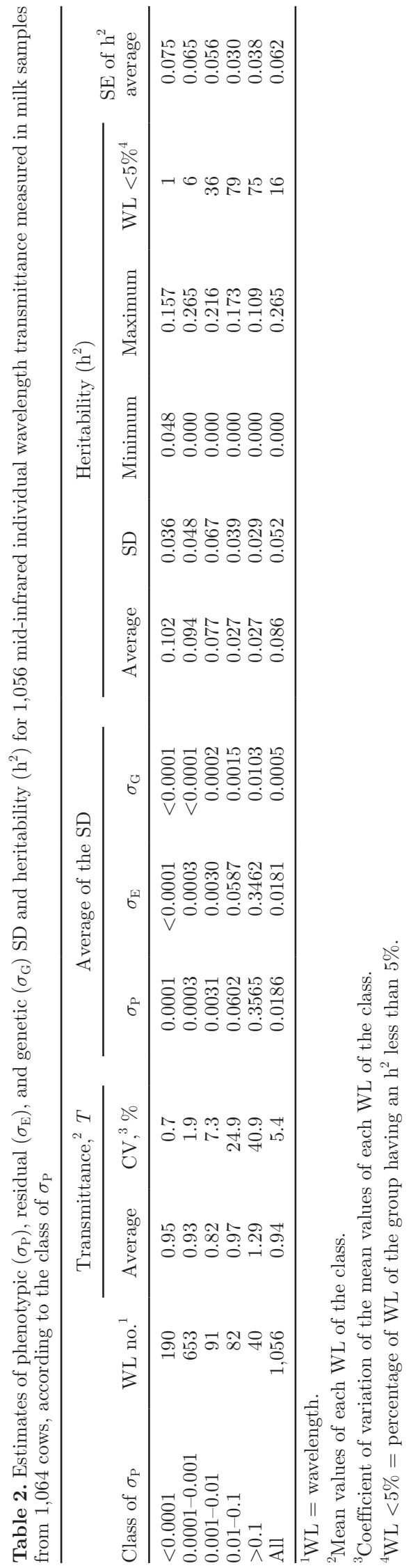

Journal of Dairy Science Vol. 96 No. 9, 2013 

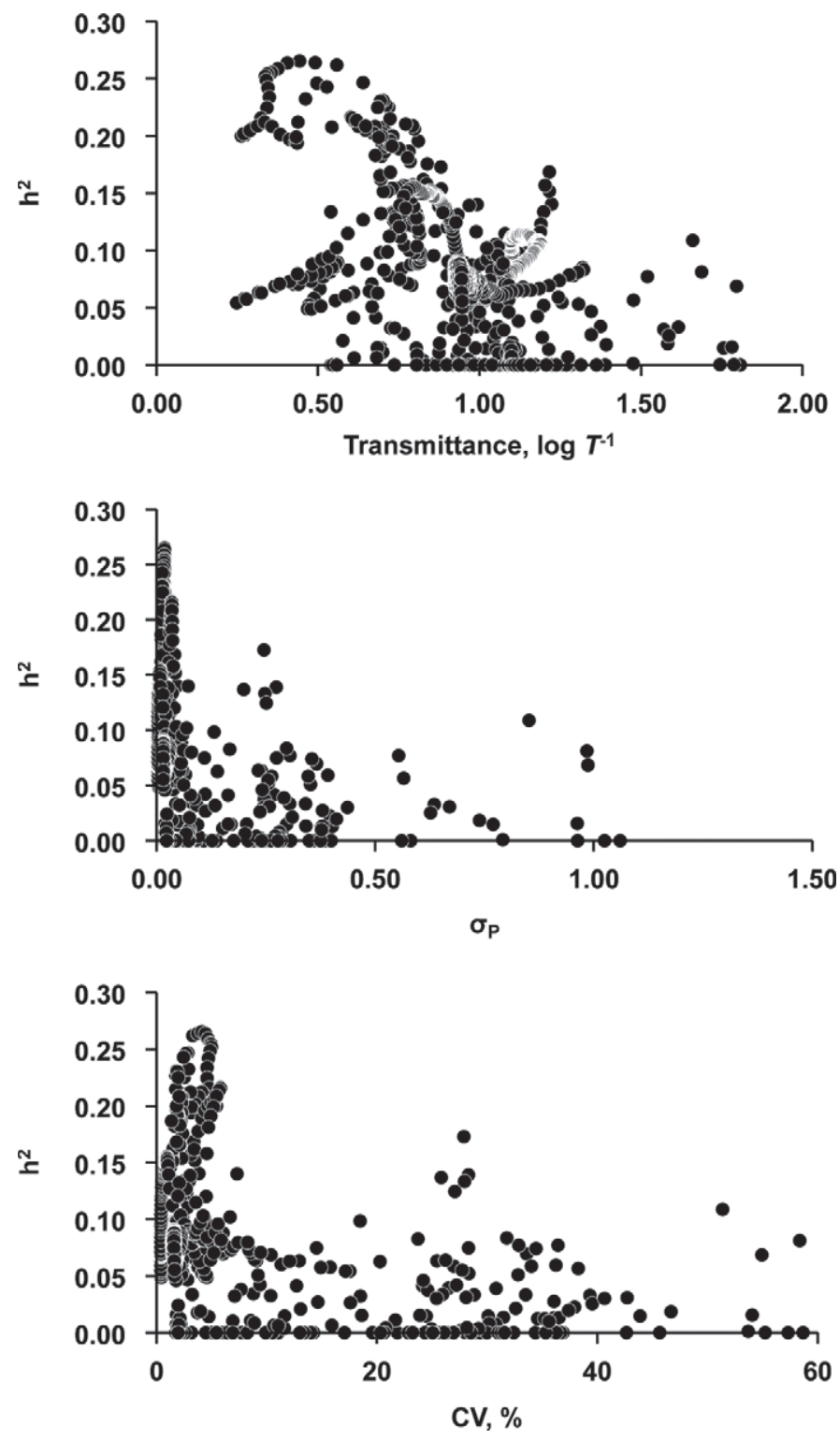

Figure 2. Plots showing the distribution of heritability $\left(\mathrm{h}^{2}\right)$ values for 1,057 individual wavelengths in relation to the average transmittance $\left(\log T^{-1}\right.$, where $T$ is transmittance), the phenotypic standard deviation $\left(\sigma_{\mathrm{P}}\right)$, and the coefficient of variation for the transmittance measured from 1,064 individual cow's milk samples.

dependence/relationship of adjacent or very close FTIR waves, we calculated the correlation coefficients between different waves separated by $1,2,3,4,5,10,20$, 30,40 , and 50 positions. As expected, the correlations tended to decrease with increasing distance between waves (Figure 3). In terms of average transmittance , the correlation between 2 consecutive positions of the spectrum was $97.8 \%$; it decreased to $88.8 \%$ after 4 positions, to $64.2 \%$ after 10 positions, and to $27.3 \%$ after 50 positions (i.e., at about $5 \%$ of the entire spectrum length). The corresponding correlations for heritability

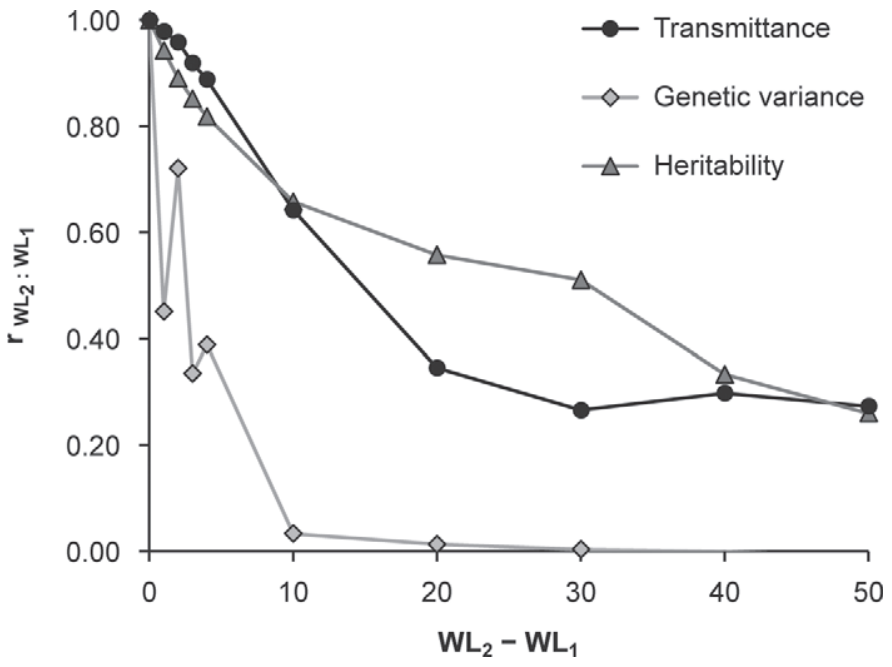

Figure 3. Correlation coefficients $\left(\mathrm{r}_{\mathrm{WL2} \text { :WL1 }}\right)$ between 2 close wavelengths according to their distance (the number of positions between them; $\mathrm{WL}_{2}-\mathrm{WL}_{1}$ ) for transmittance, genetic variance, and heritability, as estimated for 1,056 wavelengths from 1,064 individual cow milk samples.

values were $94.2,81.8,65.7$, and $26.9 \%$, respectively. In the case of genetic variance, the decrease was much more rapid, at $45.1,38.8,3.3$, and $1.0 \%$, respectively. Moreover, the decrease of genetic variance across the first group of positions was not gradual (Figure 3).

The average transmittance values of some FTIR waves that are related to specific chemical bonds in milk (Karoui et al., 2010) are shown in Tables 3, 4, 5, and 6 , together with their phenotypic, residual and genetic standard deviations and heritability coefficients. Most of the FTIR waves related to $\mathrm{C}-\mathrm{H}$-type chemical bonds had heritability coefficients greater than the overall mean (Table 3). Only 2 of the selected waves yielded null or very low heritability estimates, and they had the highest transmittance variability among the milk samples. The FTIR waves associated with C-Ctype bonds were highly heterogeneous in terms of their heritability coefficients; half of them had null or very low heritability estimates, and several had very high phenotypic variability in their transmittance (Table 4). The FTIR waves whose transmittance was influenced by $\mathrm{C}-\mathrm{O}$ - and $\mathrm{C}=\mathrm{O}$-type chemical bonds yielded more equilibrated results (Table 5), with several low or null heritability estimates balanced by some of the highest heritability estimates (primary and secondary alcohols, and aliphatic ethers). Also, some of the FTIR waves related to fluoroalkanes and nitro compounds presented heritability coefficients higher than average (Table 6).

\section{DISCUSSION}

The subdivisions of the infrared area of the spectrum vary across different sources. According to the 
Table 3. Major absorption peaks for some common $\mathrm{C}-\mathrm{H}$-type chemical bonds; their average transmittance $\left(\log T^{-1}\right.$, where $T$ is transmittance) in milk samples from 1,064 cows; their phenotypic $\left(\sigma_{\mathrm{P}}\right)$, residual $\left(\sigma_{\mathrm{E}}\right)$, and genetic $\left(\sigma_{\mathrm{G}}\right) \mathrm{SD}$; and heritability $\left(\mathrm{h}^{2}\right)$

\begin{tabular}{|c|c|c|c|c|c|c|c|c|c|c|}
\hline $\begin{array}{l}\text { Type of } \\
\text { bond }\end{array}$ & $\begin{array}{l}\text { Specific type } \\
\text { of bond }\end{array}$ & $\begin{array}{l}\text { Wavenumber } \\
\text { of absorption } \\
\text { peak }\left(\mathrm{cm}^{-1}\right)\end{array}$ & $\begin{array}{l}\text { Appearance } \\
\text { of the peak }\end{array}$ & $\begin{array}{c}\text { Transmittance, } \\
T\end{array}$ & $\mathrm{CV}, \%$ & \multicolumn{3}{|c|}{$\mathrm{SD}$} & \multicolumn{2}{|c|}{ Heritability } \\
\hline \multirow{3}{*}{ Alkyl } & \multirow{3}{*}{ Methyl } & 1,380 & Weak & 0.70 & 1.6 & 0.011 & 0.010 & 0.005 & 0.182 & 0.090 \\
\hline & & 2,870 & Medium to strong & 0.54 & 4.3 & 0.023 & 0.022 & 0.007 & 0.081 & 0.061 \\
\hline & & 2,960 & Medium to strong & 0.56 & 4.3 & 0.024 & 0.023 & 0.008 & 0.102 & 0.062 \\
\hline \multirow[t]{7}{*}{ Vinyl } & Methylene & 1,470 & Strong & 0.78 & 1.3 & 0.01 & 0.009 & 0.005 & 0.187 & 0.086 \\
\hline & Methine & 2,890 & Weak & 0.54 & 3.6 & 0.020 & 0.019 & 0.006 & 0.085 & 0.062 \\
\hline & \multirow[t]{2}{*}{$\mathrm{C}=\mathrm{CH}_{2}$} & 2,975 & Medium & 0.75 & 1.9 & 0.014 & 0.013 & 0.005 & 0.120 & 0.063 \\
\hline & & 3,080 & Medium & 0.72 & 18.5 & 0.134 & 0.132 & 0.024 & 0.032 & 0.055 \\
\hline & $\mathrm{C}=\mathrm{CH}$ & 3,020 & Medium & 1.08 & 5.2 & 0.056 & 0.054 & 0.015 & 0.070 & 0.064 \\
\hline & Monosubstituted alkenes & 990 & Strong & 0.86 & 2.3 & 0.020 & 0.018 & 0.008 & 0.165 & 0.089 \\
\hline & trans-disubstituted alkenes & 965 & Strong & 1.14 & 2.3 & 0.026 & 0.024 & 0.008 & 0.098 & 0.069 \\
\hline Aromatic & Benzene/sub. & 3,070 & Weak & 0.75 & 14.5 & 0.109 & 0.105 & 0.030 & 0.075 & 0.054 \\
\hline
\end{tabular}

International Organization for Standardization (ISO, 2007; ISO 20473:2007), the region analyzed in the present study (wavelengths 2.0 to $10.8 \mu \mathrm{m}$, corresponding to wavenumbers between 5,000 and $930 \times \mathrm{cm}^{-1}$ and frequencies of 149.9 and $27.9 \mathrm{THz}$ ) covers part of the near-infrared (NIR; from 0.78 to $3.00 \mu \mathrm{m}$ ) and MIR (from 3.00 to $50.00 \mu \mathrm{m}$ ) subdivisions. According to the International Commission on Illumination (CIE, 2004), it covers parts of infrared bands B (IR-B, from 1.40 to $3.00 \mu \mathrm{m})$ and $\mathrm{C}(\mathrm{IR}-\mathrm{C}$, from 3 to $1,000 \mu \mathrm{m})$. According to a common subdivision scheme (Byrnes, 2009), the considered infrared region begins in the shortwavelength infrared (SWIR) division (from 1.4 to 3.0 $\mu \mathrm{m})$, covers all the mid-wavelength infrared (MWIR) division (from 3.0 to $8.0 \mu \mathrm{m}$ ), and ends in the longwavelength infrared (LWIR) division (from 8.0 to 15.0 $\mu \mathrm{m})$.

\section{Heritability of the FTIR Spectrum of Milk}

To our knowledge, the only previous indirect heritability estimation of FTIR wave transmittance in milk was that reported by Soyeurt et al. (2010), wherein the authors reduced the dimensionality of the 1,060 individual waves of the FTIR spectra through principal components, first to 46 composite traits and then to only 8. They estimated genetic parameters of the principal components and then back transformed the estimated (co)variances to the original 1,060 spectral traits using a 2-step approach. With this methodology, the authors identified 2 regions of the infrared spectrum that were not useful from the genetic point of view (wavenumbers 3,668 to $3,066 \times \mathrm{cm}^{-1}$ and 1,678 to $1,616 \times \mathrm{cm}^{-1}$ ) and 3 regions with moderate to high heritability (wavenumbers 5,010 to $3,672 \times \mathrm{cm}^{-1}, 3,062$ to $1,682 \times \mathrm{cm}^{-1}$, and 1,612 to $\left.926 \times \mathrm{cm}^{-1}\right)$.

The present study used a different approach, in which the phenotypic, residual, and genetic variances and the heritability of the FTIR waves were estimated using all spectral data as a response variable, and an animal model was fitted for each individual wave of the FTIR spectrum (1,056 analyses) with the aim of obtaining direct individual estimates. Our results indicate that the large majority of FTIR waves are heritable (only 1 out of 6 had little or no heritability; Table 1), and that almost one-third of the waves had heritability coefficients higher than that obtained for milk yield from the same animals (i.e., $>10 \%$, with only 1 phenotypic observation per cow; Cecchinato et al., 2011b) or different animals of the same breed (Samoré et al., 2012; Cecchinato et al., 2013). Therefore, our results indicate that the transmittance of milk in the infrared region is at least partly controlled by the cow's genetics. Our comparison of the transmittance, phenotypic variation, genetic variation, and heritability results shown in Figure 1 indicates that the milk FTIR spectrum can be divided into 5 useful regions, as reported in Table 7.

\section{Milk FTIR Spectrum Regions: SWIR}

The first region spans wavenumber $5,000 \times \mathrm{cm}^{-1}$ to $3,673 \times \mathrm{cm}^{-1}$, corresponding to wavelengths from 2.00 to $2.72 \mu \mathrm{m}$ and frequencies from $149.9 \mathrm{THz}$ to 110.1 $\mathrm{THz}$ (Table 7). This region is part of the SWIR division (NIR) of electromagnetic radiation. The transmittance values of the waves in this SWIR region of the milk 


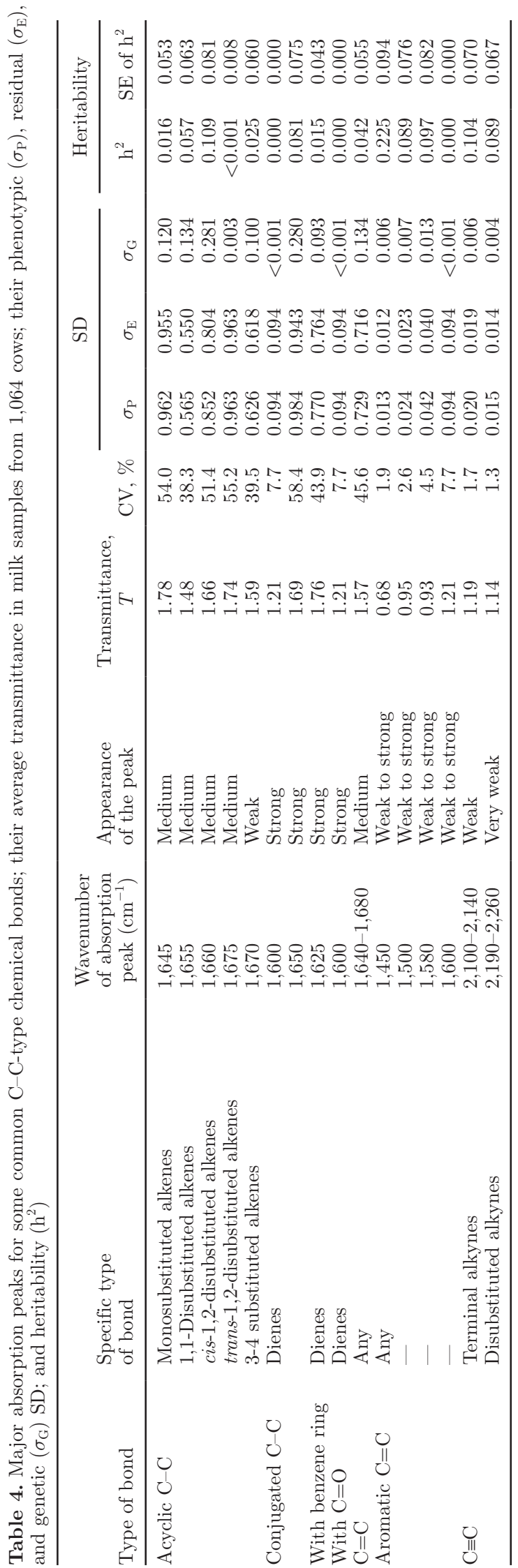

spectrum were characterized by relatively constant average values that varied little from one wave to another. The average transmittance started at $0.95 \mathrm{~T}$ (at wavenumber $5,000 \times \mathrm{cm}^{-1}$ ), decreased gradually to $0.92 T$, returned to the initial value at about $4,000 \times$ $\mathrm{cm}^{-1}$, and continued to increase up to $1.32 \mathrm{~T}$ at 3,684 $\times \mathrm{cm}^{-1}$. The variability coefficients of transmittance among the different individual milk samples were low (1.42 to $2.25 \%$ ) for all waves of the SWIR region. The genetic variability was also very similar from one wave to another, but it showed a cyclic pattern similar to that of the heritability estimates (Figure 1 ). The period (interval between 2 maxima or 2 minima) of this oscillation varied between about $65 \times \mathrm{cm}^{-1}$ for shorter wavelengths to $40 \times \mathrm{cm}^{-1}$ for longer wavelengths, whereas the amplitude (the $\mathrm{Y}$ difference between the maximum and the minimum) of the heritability coefficient oscillation decreased from about 2.5 percentage points for the shorter wavelengths to about 1.0 percentage point for the longer ones (Figure 1). Excluding wavenumber 3,673 , the 344 waves of this SWIR region had heritability coefficients that ranged from 5.0 to $9.1 \%$ (average $=7.7 \%$; $\mathrm{SD}=0.8 \%$ ), which seemed very low given the cyclic pattern observed in this region.

For this region, Soyeurt et al. (2010) reported an average transmittance similar to that found in the present study, but their estimated heritability coefficients were higher (from about 17 to about 10\%) than those estimated in the present study $(7.7 \pm 0.8 \%)$. This apparent discrepancy could be due to differences in the sampled population (primiparous Belgian Holstein vs. primiparous and multiparous Italian Brown Swiss), the sampling procedure (repeated samples from conventional milk recording vs. single ad hoc samples without preservative analyzed within $3 \mathrm{~h}$ ), the instrumentation (Foss FT 6,000 vs. Foss FT 120 MIR spectrometers), and especially the statistical procedure used (indirect heritability estimation for 1,060 individual FTIR waves through the back transformation of variance components of 46 principal components vs. direct heritability estimation for individual waves via 1,056 single-trait animal models). An evident difference between the 2 studies is found in the SWIR region, where Soyeurt et al. (2010) failed to find the cyclic heritability patterns observed in the present study. Future work will be required to determine if this was due to differences in the animals, sampling and (or) instruments, or if the previously used statistical method had some specific smoothing effect.

The SWIR region is not known to contain any absorbance peak specific to a chemical bond found in milk (Karoui et al., 2010) and is often excluded completely (Karoui et al., 2011; Soyeurt et al., 2011) or partially (Etzion et al., 2004; De Marchi et al. 2011) from the 
Table 5. Major absorption peaks for some common chemical bonds of the type $\mathrm{C}=\mathrm{O}$ and $\mathrm{C}-\mathrm{O}$; their average transmittance in the milk samples of 1,064 cows; their phenotypic $\left(\sigma_{\mathrm{P}}\right)$, residual $\left(\sigma_{\mathrm{E}}\right)$, and genetic $\left(\sigma_{\mathrm{G}}\right) \mathrm{SD}$; and heritability $\left(\mathrm{h}^{2}\right)$

\begin{tabular}{|c|c|c|c|c|c|c|c|c|c|c|c|}
\hline \multirow[b]{2}{*}{ Bond } & \multirow[b]{2}{*}{ Type of bond } & \multirow[b]{2}{*}{$\begin{array}{l}\text { Specific type } \\
\text { of bond }\end{array}$} & \multirow[b]{2}{*}{$\begin{array}{c}\text { Absorption } \\
\text { peak }\left(\mathrm{cm}^{-1}\right)\end{array}$} & \multirow[b]{2}{*}{ Appearance } & \multirow[b]{2}{*}{$\begin{array}{c}\text { Transmittance, } \\
T\end{array}$} & \multirow[b]{2}{*}{$\mathrm{CV}, \%$} & \multicolumn{3}{|c|}{$\mathrm{SD}$} & \multicolumn{2}{|c|}{ Heritability } \\
\hline & & & & & & & $\sigma_{\mathrm{P}}$ & $\sigma_{\mathrm{E}}$ & $\sigma_{\mathrm{G}}$ & $\mathrm{h}^{2}$ & $\mathrm{SE}$ of $\mathrm{h}^{2}$ \\
\hline \multirow[t]{15}{*}{$\mathrm{C}=\mathrm{O}$} & \multirow[t]{6}{*}{ Aldehyde/ketone } & Saturated aliphatic/cyclic 6-membered & 1,720 & & 1.20 & 1.2 & 0.014 & 0.014 & 0.003 & 0.052 & 0.056 \\
\hline & & $\alpha, \beta$-Unsaturated & 1,685 & & 1.26 & 17.1 & 0.215 & 0.215 & $<0.001$ & 0.000 & 0.000 \\
\hline & & Aromatic ketones & 1,685 & & 1.26 & 17.1 & 0.215 & 0.215 & $<0.001$ & 0.000 & 0.000 \\
\hline & & Cyclic 5-membered & 1,750 & & 0.62 & 10.1 & 0.062 & 0.061 & 0.016 & 0.062 & 0.057 \\
\hline & & Cyclic 4-membered & 1,775 & & 1.09 & 0.6 & 0.007 & 0.006 & 0.002 & 0.103 & 0.070 \\
\hline & & Aldehydes & 1,725 & 1 & 1.13 & 0.7 & 0.008 & 0.008 & 0.002 & 0.068 & 0.062 \\
\hline & \multirow[t]{9}{*}{ Carboxylic acids/derivates } & Saturated carboxylic acids & 1,710 & & 1.35 & 2.8 & 0.038 & 0.037 & 0.008 & 0.047 & 0.054 \\
\hline & & Unsaturated/aromatic carboxylic acids & $1,680-1,690$ & & 1.25 & 25.6 & 0.318 & 0.318 & 0.011 & 0.003 & 0.015 \\
\hline & & Esters and lactones & 1,735 & 2 & 0.79 & 6.0 & 0.047 & 0.046 & 0.012 & 0.069 & 0.060 \\
\hline & & Anhydrides & 1,760 & & 0.90 & 3.2 & 0.029 & 0.028 & 0.008 & 0.078 & 0.063 \\
\hline & & & 1,820 & & 1.10 & 0.9 & 0.010 & 0.009 & 0.003 & 0.103 & 0.070 \\
\hline & & Acyl halides & 1,800 & & 1.10 & 0.9 & 0.010 & 0.009 & 0.003 & 0.102 & 0.070 \\
\hline & & Amides & 1,650 & & 1.69 & 58.4 & 0.984 & 0.943 & 0.280 & 0.081 & 0.075 \\
\hline & & Carboxylates (salts) & $1,550-1,610$ & & 0.93 & 6.7 & 0.068 & 0.067 & 0.009 & 0.098 & 0.056 \\
\hline & & AA zwitterions & $1,550-1,610$ & & 0.93 & 6.7 & 0.068 & 0.067 & 0.009 & 0.098 & 0.056 \\
\hline \multirow[t]{8}{*}{$\mathrm{C}-\mathrm{O}$} & \multirow[t]{3}{*}{ Alcohols } & Primary & $1,040-1,060$ & Strong & 0.34 & 4.8 & 0.016 & 0.014 & 0.008 & 0.244 & 0.106 \\
\hline & & Secondary & $\sim 1,100$ & Strong & 0.38 & 3.5 & 0.014 & 0.012 & 0.006 & 0.201 & 0.110 \\
\hline & & Tertiary & $1,150-1,200$ & Medium & 0.64 & 3.2 & 0.019 & 0.018 & 0.005 & 0.069 & 0.058 \\
\hline & Phenols & Any & 1,200 & & 0.81 & 1.3 & 0.011 & 0.010 & 0.003 & 0.089 & 0.058 \\
\hline & \multirow{2}{*}{ Ethers } & Aliphatic & 1,120 & & 0.44 & 3.1 & 0.013 & 0.012 & 0.006 & 0.212 & 0.113 \\
\hline & & Aromatic & $1,220-1,260$ & & 0.75 & 1.4 & 0.011 & 0.010 & 0.004 & 0.120 & 0.071 \\
\hline & Carboxylic acids & Any & $1,250-1,300$ & & 0.78 & 1.2 & 0.009 & 0.009 & 0.003 & 0.125 & 0.082 \\
\hline & Esters & Any & $1,100-1,300$ & 3 & 0.67 & 2.2 & 0.013 & 0.013 & 0.004 & 0.121 & 0.077 \\
\hline
\end{tabular}

nfluence of conjugation (as with ketones).

${ }^{2}$ Influenced by conjugation and ring size (as with ketones).

${ }^{3}$ Two bands (distinct from ketones, which do not possess a $\mathrm{C}-\mathrm{O}$ bond). 
Table 6. General absorption peaks for some common chemical bonds of types $\mathrm{O}-\mathrm{H}, \mathrm{N}-\mathrm{H}, \mathrm{C}-\mathrm{N}, \mathrm{C}-\mathrm{X}$, and N-O; their average transmittance and CV in milk samples from 1,064 cows; their estimated genetic and phenotypic variances; and heritability $\left(\mathrm{h}^{2}\right)$ with the corresponding SE

\begin{tabular}{|c|c|c|c|c|c|c|c|c|c|c|c|}
\hline \multirow[b]{2}{*}{ Bond } & \multirow[b]{2}{*}{ Type of bond } & \multirow[b]{2}{*}{$\begin{array}{l}\text { Specific type } \\
\text { of bond }\end{array}$} & \multirow[b]{2}{*}{$\begin{array}{l}\text { Absorption } \\
\text { peak }\left(\mathrm{cm}^{-1}\right)\end{array}$} & \multirow[b]{2}{*}{ Appearance } & \multirow[b]{2}{*}{ Transmittance, $T$} & \multirow[b]{2}{*}{$\mathrm{CV}, \%$} & \multicolumn{3}{|c|}{$\mathrm{SD}^{1}$} & \multicolumn{2}{|c|}{ Heritability } \\
\hline & & & & & & & $\sigma_{\mathrm{P}}$ & $\sigma_{\mathrm{E}}$ & $\sigma_{\mathrm{G}}$ & $\mathrm{h}^{2}$ & $\mathrm{SE}$ of $\mathrm{h}^{2}$ \\
\hline \multirow[t]{4}{*}{$\mathrm{O}-\mathrm{H}$} & \multirow{2}{*}{ Alcohols, phenols } & Low concentration & $3,610-3,670$ & - & 1.11 & 2.1 & 0.023 & 0.023 & $<0.001$ & 0.002 & 0.006 \\
\hline & & High concentration & $3,200-3,400$ & Broad & 0.98 & 31.1 & 0.306 & 0.304 & 0.034 & 0.026 & 0.029 \\
\hline & \multirow{2}{*}{ Carboxylic acids } & Low concentration & $3,500-3,560$ & - & 0.93 & 4.3 & 0.034 & 0.034 & 0.003 & 0.023 & 0.028 \\
\hline & & High concentration & 3,000 & Broad & 1.01 & 3.7 & 0.037 & 0.035 & 0.011 & 0.090 & 0.071 \\
\hline \multirow[t]{4}{*}{$\mathrm{N}-\mathrm{H}$} & \multirow[t]{2}{*}{ Primary amines } & Any & $3,400-3,500$ & Strong & 0.98 & 13.8 & 0.139 & 0.139 & 0.007 & 0.009 & 0.020 \\
\hline & & Any & $1,560-1,640$ & Strong & 1.19 & 21.6 & 0.320 & 0.319 & 0.023 & 0.056 & 0.043 \\
\hline & Secondary amines & Any & $>3,000$ & Weak to medium & 0.96 & 7.1 & 0.068 & 0.067 & 0.009 & 0.059 & 0.051 \\
\hline & Ammonium ions & Any & $2,400-3,200$ & Multiple peaks & 0.84 & 6.7 & 0.056 & 0.055 & 0.009 & 0.085 & 0.066 \\
\hline \multirow[t]{6}{*}{$\mathrm{C}-\mathrm{N}$} & Aliphatic amines & Any & $1,020-1,220$ & Often overlapped & 0.50 & 3.5 & 0.016 & 0.014 & 0.006 & 0.165 & 0.088 \\
\hline & $\mathrm{C}=\mathrm{N}$ & Any & $1,615-1,700$ & & 1.52 & 38.5 & 0.609 & 0.604 & 0.078 & 0.024 & 0.037 \\
\hline & \multirow[t]{2}{*}{$\mathrm{C} \equiv \mathrm{N}$ (nitriles) } & Unconjugated & 2,250 & Medium & 1.12 & 1.2 & 0.013 & 0.013 & 0.004 & 0.086 & 0.066 \\
\hline & & Conjugated & 2,230 & Medium & 1.13 & 1.3 & 0.014 & 0.014 & 0.004 & 0.089 & 0.067 \\
\hline & $\mathrm{R}-\mathrm{N}-\mathrm{C}$ (isocyanides) & Any & $2,110-2,165$ & - & 1.18 & 1.6 & 0.019 & 0.018 & 0.006 & 0.102 & 0.069 \\
\hline & $\mathrm{R}-\mathrm{N}=\mathrm{C}=\mathrm{S}$ & Any & $1,990-2,140$ & - & 1.17 & 1.5 & 0.018 & 0.017 & 0.006 & 0.108 & 0.071 \\
\hline \multirow{2}{*}{$\mathrm{C}-\mathrm{X}$} & \multirow{2}{*}{ Fluoroalkanes } & Ordinary & $1,000-1,100$ & - & 0.42 & 4.2 & 0.016 & 0.014 & 0.008 & 0.229 & 0.106 \\
\hline & & Trifluoromethyl & $1,100-1,200$ & 2 broad bands & 0.56 & 3.1 & 0.016 & 0.016 & 0.005 & 0.125 & 0.079 \\
\hline \multirow{3}{*}{$\mathrm{N}-\mathrm{O}$} & \multirow[t]{3}{*}{ Nitro compounds } & Aliphatic & 1,540 & Strong & 0.63 & 5.5 & 0.034 & 0.030 & 0.016 & 0.208 & 0.095 \\
\hline & & & 1,380 & Weak & 0.70 & 1.6 & 0.011 & 0.010 & 0.005 & 0.182 & 0.090 \\
\hline & & Aromatic & $1,350,1,520$ & - & 0.76 & 2.7 & 0.020 & 0.018 & 0.009 & 0.173 & 0.094 \\
\hline
\end{tabular}

$\sigma_{\mathrm{P}}=$ phenotypic $\mathrm{SD} ; \sigma_{\mathrm{E}}=$ residual $\mathrm{SD} ; \sigma_{\mathrm{G}}=$ genetic $\mathrm{SD}$.

${ }^{2}$ Similar conjugation effects to $\mathrm{C}=$ 
Table 7. Characteristics of the 5 regions of the Fourier-transform infrared (FTIR) spectrum of bovine milk identified on the basis of the mean value and variability of average values of transmittance for different wavelengths $(\mu \mathrm{m})$, the variability of phenotypic $\left(\sigma_{\mathrm{P}}\right)$ and genetic $\left(\sigma_{\mathrm{G}}\right)$ SD of transmittance for different wavelengths, and the average and variability of the heritability $\left(\mathrm{h}^{2}\right)$ coefficients $^{1}$

\begin{tabular}{|c|c|c|c|c|c|c|}
\hline \multirow[b]{2}{*}{ Item } & \multicolumn{6}{|c|}{ Region } \\
\hline & $\begin{array}{c}\text { Entire } \\
\text { spectrum }\end{array}$ & SWIR & SWIR-MWIR & MWIR-1 & MWIR-2 & MWIR-LWIR \\
\hline $\mathrm{ISO}^{2}$ & NIR-MIR & NIR & NIR-MIR & MIR & MIR & MIR \\
\hline Wavenumber interval, $\times \mathrm{cm}^{-1}$ & $5,000-930$ & $5,000-3,673$ & $3,669-3,052$ & $3,048-1,701$ & $1,698-1,586$ & $1,582-930$ \\
\hline Wavelength interval, $\mu \mathrm{m}$ & $2.00-10.76$ & $2.00-2.72$ & $2.73-3.27$ & $3.28-5.88$ & $5.89-6.31$ & $6.32-10.76$ \\
\hline Frequency interval, $\mathrm{THz}$ & $149.9-27.9$ & $149.9-110.1$ & $110.0-91.5$ & $91.4-51.0$ & $50.9-47.5$ & $47.4-27.9$ \\
\hline Waves tested, no. & 1,056 & 345 & 161 & 350 & 30 & 170 \\
\hline Average transmittance, $T$ & Average & Average & Average & Average & High & Low \\
\hline Mean of average transmittance & 0.94 & 0.95 & 0.98 & 0.97 & 1.44 & 0.71 \\
\hline Waves $>1.152{ }^{3} \%$ & 10 & 3 & 6 & 16 & 87 & 5 \\
\hline Waves $<0.728,4 \%$ & 13 & 0 & 10 & 12 & 0 & 47 \\
\hline Phenotypic variability & Average & Low & High and variable & Low & High and variable & Low \\
\hline Mean of $\sigma_{\mathrm{P}}$ & 0.0551 & 0.0152 & 0.1819 & 0.0152 & 0.5102 & 0.0180 \\
\hline Waves $\sigma_{\mathrm{P}}>0.1102^{15} \%$ & 11 & 0 & 61 & 0 & 73 & 0 \\
\hline Waves $\sigma_{\mathrm{P}}<0.0276,{ }^{6} \%$ & 78 & 92 & 24 & 87 & 0 & 84 \\
\hline Genetic variability & Average & Low & High and variable & Low & High and variable & Average \\
\hline Mean of $\sigma_{\mathrm{G}}$ & 0.0088 & 0.0042 & 0.0200 & 0.0045 & 0.0627 & 0.0070 \\
\hline Waves $\sigma_{\mathrm{G}}>0.0176 .{ }^{5} \%$ & 7 & 0 & 34 & 1 & 47 & 0 \\
\hline Waves $\sigma_{\mathrm{G}}<0.0044,{ }^{6} \%$ & 64 & 92 & 52 & 61 & 47 & 30 \\
\hline Heritability & Average & Average-cyclic & Low and variable & Average & Low & High \\
\hline Mean of $h^{2}, \%$ & 8.6 & 7.6 & 2.1 & 9.6 & 1.9 & 15.9 \\
\hline Waves $\mathrm{h}^{2}>14.8 \%,{ }^{3} \%$ & 14 & 0 & 1 & 13 & 0 & 61 \\
\hline Waves $\mathrm{h}^{2}<3.4 \%,{ }^{4} \%$ & 14 & 0 & 77 & 1 & 83 & 0 \\
\hline
\end{tabular}

¿ $\quad{ }^{1}$ SWIR $=$ short-wavelength infrared $(1.40-3.00 \mu \mathrm{m}) ;$ MWIR = mid-wavelength infrared $(3.00-8.00 \mu \mathrm{m}) ;$ LWIR = long-wavelength infrared $(8.00-15.00 \mu \mathrm{m}) ;$ NIR $=$ near-infrared $(0.78-3.00 \mu \mathrm{m}) ; \mathrm{MIR}=$ mid-infrared $(3.00-50.00 \mu \mathrm{m})$

International Organization for Standardization.

ㄱ. ${ }^{3}$ Number of waves of the region (in \% of total of the region) having a value higher than the average +1.0 SD of the whole spectrum.

$\stackrel{{ }^{4}}{\equiv}$ Number of waves of the region (in \% of total of the region) having a value lower than the average -1.0 SD of the whole spectrum.

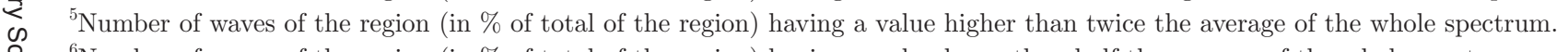

$\stackrel{\circ}{\bar{\Phi}}$. ${ }^{6}$ Number of waves of the region (in $\%$ of total of the region) having a value lower than half the average of the whole spectrum. 
calibration of major milk compounds. However, some authors have included the transmittance of the SWIR region in their studies (Soyeurt et al., 2006; Rutten et al., 2009, 2011). Further research is needed to evaluate the value of this region of the milk spectrum.

In 4 wavenumbers (from $3,681 \times \mathrm{cm}^{-1}$ to $3,669 \times$ $\mathrm{cm}^{-1}$ ), the genetic variance and heritability coefficients decreased abruptly to almost zero even though the average transmittance and the coefficients of phenotypic variability declined only slightly.

\section{Milk FTIR Spectrum Regions: SWIR-MWIR}

The second notable region of the milk FTIR spectrum (Table 7) spans wavenumber $3,669 \times \mathrm{cm}^{-1}$ to $3,052 \times \mathrm{cm}^{-1}$, corresponding to wavelengths from 2.726 to $3,277 \mu \mathrm{m}$ and frequencies from 110.0 to $91.5 \mathrm{THz}$. This region is located at the transition between SWIR and MWIR divisions of electromagnetic radiation (or between the NIR and MIR divisions according to the International Organization for Standardization).

Compared with the SWIR region, the SWIR-MWIR region shows a larger and more rapid change in average transmittance (from $0.55 \mathrm{~T}$ to $1.36 \mathrm{~T}$ ). However, the most notable aspect of this region is that the variability coefficients for the transmittance of individual waves among the milk samples of different cows remained around $2 \%$ from wavenumber $3,669 \times \mathrm{cm}^{-1}$ to about $3,530 \times \mathrm{cm}^{-1}$, and thereafter increased rapidly to values between 6 and 40\%. As shown in Figure 1, although the phenotypic standard deviation was high (with a large variation) for all wavelengths of the SWIR-MWIR region, the estimated genetic standard deviations tended to be much more variable. Quite often, 1 to 4 wavelengths with high genetic variability were followed by several wavelengths with very low genetic variability. Of the 161 wavelengths in the SWIR-MWIR region, 25 had heritability estimates greater than $5 \%$, and 5 had values greater than $10 \%(3,268,3,264,3,260,3,167$, and $\left.3,106 \times \mathrm{cm}^{-1}\right)$.

In the same region of the FTIR spectrum, Soyeurt et al. (2010) found an even wider variability in average transmittance and negligible heritability coefficients for all waves. This latter discrepancy might reflect a smoothing effect of the statistical approach adopted in the previous paper. Notably, the principal components used in the previous analysis were based on phenotypic correlations among traits. However, we see from Figure 3 that contiguous waves were much more correlated phenotypically than genetically. When using the previous technique, therefore, the genetic variance of a wave could be "diluted" for contiguous waves. Indeed, the authors of the prior study concluded that this entire region should be excluded from further analyses because of the lack of genetically interesting data. However, this region includes waves whose absorbances are characteristic of $\mathrm{C}=\mathrm{CH}_{2}$ bonds (Table $6 ; 3,080 \times \mathrm{cm}^{-1}$ ); the $\mathrm{O}-\mathrm{H}$ bonds typical of alcohols, phenols, and carboxylic acids (Table $6 ; 3,670$ to $3,610 \times \mathrm{cm}^{-1}, 3,560$ to $3,500 \times \mathrm{cm}^{-1}$, and 3,400 to $\left.3,200 \times \mathrm{cm}^{-1}\right)$; and the $\mathrm{N}-\mathrm{H}$ bonds of primary and secondary amines $\left(3,500\right.$ to $3,400 \times \mathrm{cm}^{-1}$ and $\left.>3,000 \times \mathrm{cm}^{-1}\right)$. Notably, we found that the latter regions included 18 waves that showed an appreciable heritability $(>5 \%)$.

The large phenotypic variability of this second region may be generally attributed to the fact that it is centered around the largest absorbance peak of water, which (given that water is the major component of milk) can mask the effects of minor components. To solve this problem, some authors have corrected the spectra of milk samples by subtracting the spectrum of water (Rahmelow and Hubner, 1997; Grdadolnik and Marèchal, 2001; Etzion et al., 2004), whereas others have examined dried milk samples (van der Ven et al., 2002; Wu et al., 2007, 2009). Modern FTIR instruments, such as that used for the present study, express the transmittance $T$ as the ratio between the value recorded at each analyzed wave on milk samples and the corresponding values obtained analyzing water. The whole interval of the SWIR-MWIR region is characterized by the absorbance due to the symmetric and asymmetric stretching of the $\mathrm{O}-\mathrm{H}$ bonds, including those of water. As a result, the absorbance of electromagnetic radiations of this region by both water and milk in very high and the corresponding transmission is close to null values. This explains why, when expressed as ratio between 2 very low numbers, the transmittance $T$ is characterized by a very high phenotypic variability. Nevertheless, the presence of the absorbance peaks typical of other minor components of milk explains the presence of sometimes high genetic variability for some waves of the region.

\section{Milk FTIR Spectrum Regions: MWIR-1}

The third relevant region of the FTIR spectrum spans wavenumber $3,048 \times \mathrm{cm}^{-} 1$ to $1,701 \times \mathrm{cm}^{-1}$, corresponding to wavelengths from 3.281 to $5.878 \mu \mathrm{m}$ and frequencies from 91.4 to $51.0 \mathrm{THz}$. This region is part of the MWIR (or MIR) division of electromagnetic radiation.

Similar to the SWIR region, the MWIR-1 region shows more gradual changes in terms of transmittance, phenotypic variability, and genetic variability (Figure 1) compared with the SWIR-MWIR region. The first part of the MWIR-1 region showed a decrease in the average transmittance (the minimum value of the entire FTIR spectrum, $0.25 T$, was registered at wavenumber 
$2,924 \times \mathrm{cm}^{-1}$ ) and a parallel increase in the coefficient of variability (which reached an overall maximum of $17.5 \%$, corresponding to the minimum transmittance). The heritability values were mostly between 5 and $10 \%$. In the subregion following wavenumber 2,836 $\times \mathrm{cm}^{-1}$, we observed medium average transmittance values $(0.72$ to $0.93 \mathrm{~T})$ and very low coefficients of variability (mostly below 1\%), but moderate coefficients of heritability (mostly close to $15 \%$ ). After wavenumber $2,600 \times \mathrm{cm}^{-1}$, the average transmittance values varied gradually, increasing from $0.93 T$ to $1.19 T$, and then decreasing to $1.00 \mathrm{~T}$. The coefficients of variability for transmittance were always below $2 \%$ and the heritability coefficients gradually decreased from 9 to $5 \%$, and then increased once more to around $10 \%$. The last small subregion (to $1,701 \times \mathrm{cm}^{-1}$ ) showed high variability in the average transmittance values of different waves and the variability coefficients for the transmittance of a given wave among animals. The heritability coefficients gradually decreased toward null values.

The average transmittance values of the different waves of the MWIR-1 region showed a pattern very similar to that described by Soyeurt et al. (2010). However, although the heritability coefficients showed similar trends in the 2 papers, those obtained in the present study were about half those in the previous report and this discrepancy can reflect differences in the cow population, sampling, instruments, data pretreatment, and statistical analyses adopted.

This region is very important for the estimation of milk constituents because it contains the major absorbance peaks for $\mathrm{C}-\mathrm{H}$ bonds (Table 3 ), $\mathrm{C}=\mathrm{O}$ bonds (Table 4), $\mathrm{C}-\mathrm{N}$ bonds, and $\mathrm{N}-\mathrm{H}$ bonds (Table 6). In studies using MIR spectrometers that apply fixed filters (instead of FTIR technology) this region is the center for the "fat A" and "fat B" filters, which usually span 1,786 to $1,725 \times \mathrm{cm}^{-1}$ and 2,870 to $2,778 \times \mathrm{cm}^{-1}$, respectively (Lynch et al., 2006; Kaylegian et al., 2009).

It is worth noting that the heritability of the milk fat content previously estimated for the same cows from the same FTIR spectra of the current study was $10.8 \%$ (Cecchinato et al., 2011b), which is close to the average heritability of the transmittance in this region of the spectrum. In the same study, Cecchinato et al. (2011b) found that the heritability of fat content in a Holstein-Friesian population (using milk samples analyzed using the same procedures, laboratory, and statistical model) was much higher at $36.4 \%$. The low estimate of fat heritability should not be considered specific to the herds and animals sampled for the current study, as similar estimates have been obtained using different data sets from the same breed (Dal Zotto et al., 2007; Tiezzi et al., 2011; Macciotta et al., 2012). Furthermore, the low heritability of milk components (especially fat percentage) in the Italian Brown Swiss breed can at least partly explain (or be explained by) the lower heritability estimates for the transmittance of the FTIR waves found in the present study compared with those obtained by Soyeurt et al. (2010).

\section{Milk FTIR Spectrum Regions: MWIR-2}

The fourth, very short, region of the FTIR spectrum (the MWIR-2 region; Table 7) spans wavenumber 1,698 $\times \mathrm{cm}^{-1}$ to $1,586 \times \mathrm{cm}^{-1}$ (corresponding to wavelengths 5.891 to $6.307 \mu \mathrm{m}$ and frequencies of 50.9 to $47.5 \mathrm{THz}$ ) and lies within the MWIR part of the FTIR spectrum. Similar to the SWIR-MWIR region, the MWIR-2 region has a peak of absorbance for water that increases the variability coefficient for the transmittance among different milk samples within individual waves (Figure 1). In this case, the type of bond that causes a very high absorbance of the electromagnetic radiations of this region of the spectrum is $\mathrm{H}-\mathrm{O}-\mathrm{H}$ bending. So, the ratio $T$ between 2 very low transmission values of milk and water yields a high phenotypic variability of all the waves of the region. At wavenumber 1,628 $\times$ $\mathrm{cm}^{-1}$, the average transmittance reached $1.81 \mathrm{~T}$, which was the highest value observed across the entire milk FTIR spectrum. The same wavelength also yielded the greatest coefficient of variation $(58.7 \%)$. Similar to the SWIR-MWIR region, the MWIR-2 region showed a large variability in the genetic standard deviations of different waves; several waves had very low estimates, whereas others (from wavenumber 1,667 to $1,651 \times$ $\mathrm{cm}^{-1}$ ) showed the highest genetic standard deviations registered in our experiments. Because the increase in genetic variability was generally lower than the increase in phenotypic variability, the heritability of the transmittance in this region was generally close to zero; the sole exception was the cited interval, which had $10.9 \%$ heritability at wavenumber $1,659 \times \mathrm{cm}^{-1}$.

Soyeurt et al. (2010) also observed a peak of transmittance (expressed as ratio $\mathrm{R}$ between the values of milk and water) in this region, but it was not comparable to the peaks in the second region. Moreover they obtained a more rounded pattern of heritability, with very low values and no evidence of the spike that we observed in the middle of the region. Based on their findings, Soyeurt et al. (2010) concluded that data from this region should not be used for genetic purposes. However, we would argue that this MWIR-2 region of the milk FTIR spectrum is chemically important because it contains other bond-related absorption peaks beyond that due to $\mathrm{H}-\mathrm{O}-\mathrm{H}$ bending, such as those for acyclic and conjugated $\mathrm{C}-\mathrm{C}, \mathrm{C}=\mathrm{C}$ (Table 4), $\mathrm{C}=\mathrm{O}$ (Table 5 ), $\mathrm{C}-\mathrm{N}$, and $\mathrm{N}-\mathrm{H}$ (Table 6) bonds, which in some cases imbue the interval with appreciable heritability coefficients. In the 
future, efforts should be made to reduce interference from the water absorption peak and obtain useful information from this region. In a previous study, Karoui et al. (2011) corrected the spectra of milk samples for the spectrum of pure water, and successfully exploited information from this region to classify ewe's milk according to feeding regimen and DIM.

\section{Milk FTIR Spectrum Regions: MWIR-LWIR}

The last important region of the milk FTIR spectrum includes 170 waves in the interval from wavenumber 1,582 to $930 \times \mathrm{cm}^{-1}$ (corresponding to wavelengths 6.322 to $10.76 \mu \mathrm{m}$ and frequency 47.4 to $27.9 \mathrm{THz}$ ). According to a common subdivision scheme (Byrnes, 2009), half of this region falls in the MWIR division and the other half falls in the LWIR division.

This MWIR-LWIR region did not show important water-related interference or the associated high phenotypic variability of transmittance among different samples, but it was still more variable than the first and third regions. The average transmittance values of different waves varied between 1.0 and $0.6 T$ (at wavenumber $1,173 \times \mathrm{cm}^{-1}$ ), decreased to the second lowest value observed throughout (0.26 $T$ at wavenumber $\left.1,076 \times \mathrm{cm}^{-1}\right)$, and then increased rapidly toward the end of the spectrum (1.22 $T$ at wavenumber $930 \times$ $\left.\mathrm{cm}^{-1}\right)$. The coefficients of variability ranged between 1 and $6 \%$, with the highest values corresponding to waves with the lowest transmittance. All of the heritability coefficients were higher than 5\%; 56 waves exhibited heritability estimates greater than $20 \%$, all concentrated in 3 peaks (Figure 1; from 1,570 to $1,616 \times$ $\mathrm{cm}^{-1}$, from 1,470 to $1,381 \times \mathrm{cm}^{-1}$, and from 1,134 to $\left.992 \times \mathrm{cm}^{-1}\right)$.

The trends for both transmittance and heritability found in the present study were similar to those found by Soyeurt et al. (2010), although the heritability estimates in the present study are smaller than those found in the previous paper.

This MWIR-LWIR region is known to be very important in FTIR-based analysis, and is sometimes referred to as the "fingerprint region" of the sample (Karoui et al., 2011) because it contains important information regarding the chemical structure of the analyzed matter. This region harbors several peaks of absorbance relative to $\mathrm{C}-\mathrm{H}$ bonds (Table 3 ), aromatic $\mathrm{C}=\mathrm{C}$ bonds (Table 4), $\mathrm{C}-\mathrm{O}$ bonds (Table 5), and $\mathrm{N}-\mathrm{O}$ bonds (Table 6 ). In the case of milk, these features mainly correspond to carbohydrates and organic acids (Picque et al., 1993). The bands of the region were previously reported in detail by Karoui et al. (2011). Mid-infrared spectrometers that use fixed filters typically center the filters for protein and lactose in this region, usually at 1,547 to
$1,478 \times \mathrm{cm}^{-1}$ and 1,049 to $1,042 \times \mathrm{cm}^{-1}$, respectively (Grappin et al., 2000; Kaylegian et al., 2006; Lynch et al., 2006). The heritability of the protein content of milk previously estimated from the same cows using the same FTIR spectra was $29.0 \%$ (Cecchinato et al., 2011b), which was much higher than the estimated fat content but only slightly higher than the average heritability of the transmittance in this region of the FTIR spectrum.

\section{CONCLUSIONS}

This study shows that the transmittance of the bovine milk FTIR spectrum is heritable for most individual waves in the wavenumber interval from 5,000 to 930 $\times \mathrm{cm}^{-1}$. Furthermore, the transmittance of contiguous FTIR waves is much more correlated in terms of average value and phenotypic variation than in terms of genetic variation. We identified and characterized 5 important regions of the milk spectrum on the basis of average transmittance, phenotypic variability, genetic variability, and heritability coefficients. Two regions (the SWIR-MWIR and the MWIR-2 region), show a very high phenotypic within-wave variability of transmittance for the individual milk samples. This is caused by the very high absorption peaks of water, which is the most important component of milk. In these regions, the within-wave genetic variability of the transmittance of individual milk samples is often high and variable but the heritability is generally very low (with some exceptions). Despite interference from water absorbance, these regions harbor the absorbance peaks of chemical bonds that are important for the quantification of some non-water milk components and, thus, warrant further investigation at the phenotypic and genetic levels. The other 3 FTIR spectrum regions identified herein contain many absorbance peaks corresponding to important chemical bonds, have much lower phenotypic and genetic variability of transmittance within individual waves, and have higher and less variable heritability coefficients. Among them, the SWIR region (NIR) shows an interesting cyclic pattern in its heritability coefficients of transmittance, the MWIR-1 region is particularly important for fats, and the MWIR-LWIR region, which is also known as the fingerprint region, has 3 areas of relatively high heritability. These results provide new insight into the direct relationships between a cow's genes and the infrared spectra of her milk, which are influenced by the complex effects of genes on the animal's morphology and physiology, the metabolism of the udder gland, and the chemical composition and technological properties of the secreted milk. This improved understanding of the genetic basis of transmittance data suggests that 
the FTIR spectra of milk could potentially be used not only indirectly, through phenotypic predictions of specific milk quality and technological traits, but also directly for the genetic improvement of dairy species.

\section{ACKNOWLEDGMENTS}

The authors thank Trento Province (Italy) for financial support, the Italian Brown Swiss Cattle Breeders Association (ANARB; Verona, Italy) for supplying pedigree information, and the Superbrown Consortium of Bolzano and Trento (Italy) for technical support.

\section{REFERENCES}

Arnould, V. M.-R., H. Soyeurt, N. Gengler, F. G. Colinet, M. V. Georges, C. Bertozzi, D. Portetelle, and R. Renaville. 2009. Genetic analysis of lactoferrin content in bovine milk. J. Dairy Sci. 92:2151-2158.

Barbano, D. M., and J. M. Lynch. 2006. Major advances in testing of dairy products: Milk component and dairy product attribute testing. J. Dairy Sci. 89:1189-1194.

Bastin, C., D. P. Berry, H. Soyeurt, and N. Gengler. 2012. Genetic correlations of days open with production traits and contents in milk of major fatty acids predicted by mid-infrared spectrometry. J. Dairy Sci. 95:6113-6121.

Bittante, G., M. Penasa, and A. Cecchinato. 2012. Invited review: Genetics and modeling of milk coagulation properties. J. Dairy Sci. 95:6843-6870.

Bonfatti, V., G. Di Martino, and P. Carnier. 2011. Effectiveness of mid-infrared spectroscopy for the prediction of detailed protein composition and contents of protein genetic variants of individual milk of Simmental cows. J. Dairy Sci. 94:5776-5785.

Brandt, M., A. Haeussermann, and E. Hartung. 2010. Invited review: Technical solutions for analysis of milk constituents and abnormal milk. J. Dairy Sci. 93:427-436.

Cecchinato, A., C. Cipolat-Gotet, J. Casellas, M. Penasa, A. Rossoni, and G. Bittante. 2013. Genetic analysis of rennet coagulation time, curd-firming rate, and curd firmness assessed over an extended testing period using mechanical and near-infrared instruments. J. Dairy Sci. 96:50-62.

Cecchinato, A., M. De Marchi, L. Gallo, G. Bittante, and P. Carnier. 2009. Mid-infrared spectroscopy predictions as indicator traits in breeding programs for enhanced coagulation properties of milk. J. Dairy Sci. 92:5304-5313.

Cecchinato, A., M. De Marchi, M. Penasa, A. Albera, and G. Bittante. 2011a. Near-infrared reflectance spectroscopy predictions as indicator traits in breeding programs for enhanced beef quality. J. Anim. Sci. 89:2687-2695.

Cecchinato, A., M. De Marchi, M. Penasa, J. Casellas, S. Schiavon, and G. Bittante. 2012. Genetic analysis of beef fatty acid composition predicted by near-infrared spectroscopy. J. Anim. Sci. 90:429-438.

Cecchinato, A., M. Penasa, M. De Marchi, L. Gallo, G. Bittante, and P. Carnier. 2011b. Genetic relationships of coagulation properties with milk yield, quality, and acidity estimated using coagulating and noncoagulating milk information in Brown Swiss and Holstein-Friesian cows. J. Dairy Sci. 94:4205-4213.

CIE (International Commission on Illumination). 2004. Colorimetry. 3rd ed. CIE 015. CIE, Vienna Austria.

D'Amico, A., C. Di Natale, F. Lo Castro, S. Iarossi, A. Catini, and E. Martinelli. 2009. Volatile compounds detection by IR acousto-optic detectors. Pages 21-22 in Unexploded Ordnance Detection and Mitigation. J. Byrnes, ed. Springer, Dordrecht, the Netherlands.

Dal Zotto, R., M. De Marchi, A. Cecchinato, M. Penasa, M. Cassandro, P. Carnier, L. Gallo, and G. Bittante. 2008. Reproducibility and repeatability of measures of milk coagulation properties and predictive ability of mid-infrared reflectance spectroscopy. J. Dairy Sci. 91:4103-4112.

Dal Zotto, R., M. De Marchi, C. Dalvit, M. Cassandro, L. Gallo, P. Carnier, and G. Bittante. 2007. Heritabilities and genetic correlations of body condition score and calving interval with yield, somatic cell score, and linear type traits in Brown Swiss cattle. J. Dairy Sci. 90:5737-5743.

De Marchi, M., C. C. Fagan, C. P. O'Donnell, A. Cecchinato, R. Dal Zotto, M. Cassandro, M. Penasa, and G. Bittante. 2009. Prediction of coagulation properties, titratable acidity, and $\mathrm{pH}$ of bovine milk using mid-infrared spectroscopy. J. Dairy Sci. 92:423-432.

De Marchi, M., M. Penasa, A. Cecchinato, M. Mele, P. Secchiari, and G. Bittante. 2011. Effectiveness of mid-infrared spectroscopy to predict fatty acid composition of Brown Swiss bovine milk. Animal 5:1653-1658.

Etzion, Y., R. Linker, U. Cogan, and I. Shmulevich. 2004. Determination of protein concentration in raw milk by mid-infrared Fourier transform infrared/attenuated total reflectance spectroscopy. J. Dairy Sci. 87:2779-2788.

Fagan, C. C., C. Everard, C. P. O'Donnell, G. Downey, E. M. Sheehan, C. M. Delahunty, and D. J. O'Callaghan. 2007a. Evaluating midinfrared spectroscopy as a new technique for predicting sensory texture attributes of processed cheese. J. Dairy Sci. 90:1122-1132.

Fagan, C. C., C. Everard, C. P. O'Donnell, G. Downey, E. M. Sheehan, C. M. Delahunty, D. J. O'Callaghan, and V. Howard. 2007b. Prediction of processed cheese instrumental texture and meltability by mid-infrared spectroscopy coupled with chemometric tools. J. Food Eng. 80:1068-1077.

Grappin, R., D. Lefier, and G. Mazerolles. 2000. Analyse du lait et des produits laitiers. Pages 497-540 in La spectroscopie infrarouge et ses applications analytiques. D. Bertrand and E. Dufour, ed. Tec \& Doc, Paris, France.

Grdadolnik, J., and Y. Maréchal. 2001. Bovine serum albumin observed by infrared spectrometry. II. Hydration mechanisms and interaction configurations of embedded $\mathrm{H}_{2} \mathrm{O}$ molecules. Biopolymers 62:54-67.

Groeneveld, E. 1996. User's Guide: REML-VCE-A multivariate multimodel restricted maximum likelihood (co)variance components estimation package. Version 4.0. Inst. Anim. Husbandry Anim. Behav., Fed. Agric. Res. Ctr., Neustadt, Germany.

ICAR (International Committee for Animal Recording). 2012. International agreement of recording practices-Guidelines approved by the General Assembly held in Cork, Ireland on June 2012. ICAR, Rome. Italy.

ISO. 2007. ISO 20473:2007 (Optics and photonics - Spectral bands. International Organization for Standardization (ISO), Geneva, Switzerland.

Karoui, R., J.-O. Bosset, G. Mazerolles, A. Kulmyrzaev, and É. Dufour. 2005a. Monitoring the geographic origin of both experimental French Jura hard cheeses and Swiss Gruyère and L'Etivaz PDO cheeses using mid-infrared and fluorescence spectroscopies: A preliminary investigation. Int. Dairy J. 15:275-286.

Karoui, R., G. Downey, and C. Blecker. 2010. Mid-infrared spectroscopy coupled with chemometrics: A tool for the analysis of intact food systems and the exploration of their molecular structure-quality relationships - A review. Chem. Rev. 110:6144-6168.

Karoui, R., É. Dufour, L. Pillonel, E. Schaller, D. Picque, T. Cattenoz, and J.-O. Bosset. 2005b. The potential of combined infrared and fluorescence spectroscopies as a method of determination of the geographic origin of Emmental cheeses. Int. Dairy J. 15:287-298.

Karoui, R., M. Hammami, H. Rouissi, and C. Blecker. 2011. Mid infrared and fluorescence spectroscopies coupled with factorial discriminant analysis technique to identify sheep milk from different feeding systems. Food Chem. 127:743-748.

Kaylegian, K. E., G. E. Houghton, J. M. Lynch, J. R. Fleming, and D. M. Barbano. 2006. Calibration of infrared milk analyzers: Modified milk versus producer milk. J. Dairy Sci. 89:2817-2832

Kaylegian, K. E., J. M. Lynch, J. R. Fleming, and D. M. Barbano. 2009. Influence of fatty acid chain length and unsaturation on midinfrared milk analysis. J. Dairy Sci. 92:2485-2501. 
Koca, N., L. E. Rodriguez-Saona, W. J. Harper, and V. B. Alvarez. 2007. Application of Fourier transform infrared spectroscopy for monitoring short-chain free fatty acids in Swiss cheese. J. Dairy Sci. 90:3596-3603.

Laporte, M.-F., R. Martel, and P. Paquin. 1998. The near-infrared optic probe for monitoring rennet coagulation in cow's milk. Int. Dairy J. 8:659-666.

Leitner, G., Y. Lavi, U. Merin, L. Lemberskiy-Kuzin, and G. Katz. 2011. Online evaluation of milk quality according to coagulation properties for its optimal distribution for industrial applications. J. Dairy Sci. 94:2923-2932.

Lynch, J. M., D. M. Barbano, M. Schweisthal, and J. R. Fleming. 2006. Precalibration evaluation procedures for mid-infrared milk analyzers. J. Dairy Sci. 89:2761-2774.

Macciotta, N. P. P., A. Cecchinato, M. Mele, and G. Bittante. 2012. Use of multivariate factor analysis to define new indicator variables for milk composition and coagulation properties in Brown Swiss cows. J. Dairy Sci. 95:7346-7354.

Martín-del-Campo, S. T., D. Picque, R. Cosío-Ramírez, and G. Corrieu. 2007. Evaluation of chemical parameters in soft mold-ripened cheese during ripening by mid-infrared spectroscopy. J. Dairy Sci. 90:3018-3027.

McParland, S., G. Banos, E. Wall, M. P. Coffey, H. Soyeurt, R. F. Veerkamp, and D. P. Berry. 2011. The use of mid-infrared spectrometry to predict body energy status of Holstein cows. J. Dairy Sci. 94:3651-3661.

O'Callaghan, D. J., C. P. O'Donnell, and F. A. Payne. 2002. Review of systems for monitoring curd setting during cheesemaking. Int. J. Dairy Technol. 55:65-74

Payne, F. A., C. L. Hicks, and P.-S. Shen. 1993. Predicting optimal cutting time of coagulation milk using diffuse reflectance. J. Dairy Sci. 76:48-61.

Picque, D., D. Lefier, R. Grappin, and G. Corrieu. 1993. Monitoring of fermentation by infrared spectrometry: Alcoholic and lactic fermentations. Anal. Chim. Acta 279:67-72.

Pillonel, L., W. Luginbühl, D. Picque, E. Schaller, R. Tabacchi, and J. O. Bosset. 2003. Analytical methods for the determination of the geographic origin of Emmental cheese: Mid- and near-infrared spectroscopy. Eur. Food Res. Technol. 216:174-178.

Rahmelow, K., and W. Hubner. 1997. Infrared spectroscopy in aqueous solution: Difficulties and accuracy of water subtraction. Appl. Opt. 51:160-170.

Rutten, M. J. M., H. Bovenhuis, J. M. L. Heck, and J. A. M. van Arendonk. 2011. Predicting bovine milk protein composition based on Fourier transform infrared spectra. J. Dairy Sci. 94:5683-5690.

Rutten, M. J. M., H. Bovenhuis, K. A. Hettinga, H. J. F. van Valenberg, and J. A. M. van Arendonk. 2009. Predicting bovine milk fat composition using infrared spectroscopy based on milk samples collected in winter and summer. J. Dairy Sci. 92:6202-6209.

Rutten, M. J. M., H. Bovenhuis, and J. A. M. van Arendonk. 2010. The effect of the number of observations used for Fourier transform infrared model calibration for bovine milk fat composition on the estimated genetic parameters of the predicted data. J. Dairy Sci. 93:4872-4882.

Samoré, A. B., F. Canavesi, A. Rossoni, and A. Bagnato. 2012. Genetics of casein content in Brown Swiss and Italian Holstein dairy cattle breeds. Ital. J. Anim. Sci. 11:e36.
Soyeurt, H., D. Bruwier, J.-M. Romnee, N. Gengler, C. Bertozzi, D. Veselko, and P. Dardenne. 2009. Potential estimation of major mineral contents in cow milk using mid-infrared spectrometry. J. Dairy Sci. 92:2444-2454.

Soyeurt, H., F. G. Colinet, V. M.-R. Arnould, P. Dardenne, C. Bertozzi, R. Renaville, D. Portetelle, and N. Gengler. 2007a. Genetic variability of lactoferrin content estimated by mid-infrared spectrometry in bovine milk. J. Dairy Sci. 90:4443-4450.

Soyeurt, H., P. Dardenne, F. Dehareng, C. Bastin, and N. Gengler 2008a. Genetic parameters of saturated and monounsaturated fatty acid content and the ratio of saturated to unsaturated fatty acids in bovine milk. J. Dairy Sci. 91:3611-3626.

Soyeurt, H., P. Dardenne, F. Dehareng, G. Lognay, D. Veselko, M. Marlier, C. Bertozzi, P. Mayeres, and N. Gengler. 2006. Estimating fatty acid content in cow milk using mid-infrared spectrometry. J. Dairy Sci. 89:3690-3695.

Soyeurt, H., F. Dehareng, N. Gengler, S. McParland, E. Wall, D. P. Berry, and M. Coffey. 2011. Mid-infrared prediction of bovine milk fatty acids across multiple breeds, production systems, and countries. J. Dairy Sci. 94:1657-1667.

Soyeurt, H., F. Dehareng, P. Mayeres, C. Bertozzi, and N. Gengler. 2008b. Variation of $\Delta^{9}$-desaturase activity in dairy cattle. J. Dairy Sci. 91:3211-3224.

Soyeurt, H., A. Gillon, S. Vanderick, P. Mayeres, C. Bertozzi, and N. Gengler. 2007b. Estimation of heritability and genetic correlations for the major fatty acids in bovine milk. J. Dairy Sci 90:4435-4442.

Soyeurt, H., I. Misztal, and N. Gengler. 2010. Genetic variability of milk components based on mid-infrared spectral data. J. Dairy Sci. 93:1722-1728

Subramanian, A., W. J. Harper, and L. E. Rodriguez-Saona. 2009. Cheddar cheese classification based on flavor quality using a novel extraction method and Fourier transform infrared spectroscopy. J. Dairy Sci. 92:87-94.

Tiezzi, F., C. Maltecca, M. Penasa, A. Cecchinato, Y. M. Chang, and G. Bittante. 2011. Genetic analysis of fertility in the Italian Brown Swiss population using different models and trait definitions. J. Dairy Sci. 94:6162-6172.

van der Ven, C., S. Muresan, H. Gruppen, D. B. A. de Bont, K. B. Merck, and A. G. J. Voragen. 2002. FTIR spectra of whey and casein hydrolysates in relation to their functional properties. J. Agric. Food Chem. 50:6943-6950.

Woodcock, T., C. Fagan, C. P. O'Donnell, and G. Downey. 2008. Application of near and mid-infrared spectroscopy to determine cheese quality and authenticity. Food Bioprocess Technol. 1:117-129.

Wright, S. 1922. Coefficients of inbreeding and relationship. Am. Nat. $56: 330-338$

Wu, D., S. Feng, and Y. He. 2007. Infrared spectroscopy technique for the nondestructive measurement of fat content in milk powder. J. Dairy Sci. 90:3613-3619.

Wu, D., Y. He, J. Shi, and S. Feng. 2009. Exploring near and midinfrared spectroscopy to predict trace iron and zinc contents in powdered milk. J. Agric. Food Chem. 57:1697-1704. 